\title{
Effect of Advanced Trauma Life Support (ATLS) on the Time Needed for Treatment in Simulated Mountain Medicine Emergencies
}

\author{
Franck G Billmann, MD, PhD, FACS; Claude Burnett, MD; Stefanie Welke; Therezia Bokor-Billmann, MD \\ From the Department of General and Visceral Surgery (Dr Billmann); and the Department of Thoracic Surgery (Dr Bokor-Billmann), University \\ Hospital Freiburg, Freiburg, Germany; the Department of Surgery, USA Health Center, Vicenza, Italy (Dr Burnett); and the Department of \\ General Surgery, St. Vincentius Kliniken, Karlsruhe, Germany (Ms Welke).
}

\begin{abstract}
Objective.-The number of tourists exploring mountainous areas continues to increase. As a consequence, rescue operations are increasing, especially for trauma and polytrauma victims. The outcome of such patients depends greatly on the duration of the prehospital stabilization. Limited medical training of mountain rescuers may adversely affect the outcome of patients. There is no study investigating high altitude trauma treatment. The aim of this study is to analyze the impact of advanced trauma life support (ATLS) principles in mountain trauma, and to discuss a possible role of ATLS in mountain medicine education programs.

Methods.-We designed 5 tasks representing life-threatening trauma problems encountered in mountain rescue. They were used to evaluate the physician's ability to adequately diagnose and react to trauma situations. We created 2 groups: 1) the ATLS group, consisting of physicians who passed the ATLS course and the mountain medicine course, and 2) the non-ATLS group, consisting of physicians who did not obtain the ATLS training but who did pass the mountain medicine course. We compared the time spent to complete the tasks in both groups.

Results.-In 4 of the 5 tasks (airway, breathing, circulation, and combination), the ATLS group completed the task significantly faster. In the environment task, however, the ATLS group was slower. This was the only not significant result.

Conclusions.-ATLS principles adapted and implemented for high altitude medicine education may have a positive impact on high altitude trauma treatment and outcomes.
\end{abstract}

Key words: ATLS, mountain medicine, trauma, education

\section{Introduction}

In the last several years, mountain activities such as skiing or alpine climbing have increased. ${ }^{1}$ Because high altitude sports or activity impose enormous physical demands, accidents are inevitable. ${ }^{2}$ As a consequence, rescue operations have increased, especially for trauma. ${ }^{3}$ The consequences of injury in this environment can be serious, and appropriate medical care is required. The outcome of such patients depends greatly on the duration of the prehospital stabilization. ${ }^{4}$ Thus, limited medical

Corresponding author: Franck Billmann, MD, Department of General and Visceral Surgery, University Hospital Freiburg, Hugstetter Strasse 55, D-79106, Freiburg im Breisgau, Germany (e-mail: franck. billmann@wanadoo.fr). training of mountain rescuers may adversely affect outcomes. Several studies were published in the last few years, ${ }^{5-8}$ which analyze mountain medical education and propose guidelines for training. However, data analyzing the physician's performance in high altitude conditions in the case of trauma are scarce. Advanced trauma life support (ATLS) is widely accepted as the standard of care for initial assessment and treatment in trauma centers; it has been shown to improve physician's performance. There is no study analyzing the impact of ATLS principles on physician performance in the field of high altitude trauma treatment.

The aim of this study is to analyze the impact of ATLS principles in mountain medicine trauma and to discuss a possible role of ATLS in mountain medicine education programs. 


\section{Methods}

\section{PHYSICIANS}

Thirty physicians (19 women and 11 men) who completed the theoretical and practical mountain medicine training (diplôme universitaire de médecine de montagne) in France were included in our study. This training is a theoretical and practical 1-year university certificate training, representing 100 hours. ${ }^{9}$ A 1-week practical training takes place at the Refuges des Cosmiques (Chamonix, France). The educational main topics of this university diploma are 1) physiologic modifications caused by hypoxia, 2) thermoregulation, 3) high altitude pathology, 4) physiologic aspects of alpinism, 5) traumatology in austere and remote environments, 6) altitude and nutrition, 7) training and altitude, 8) scientific research in high altitude: problems and methodology, 9) hypothermia and cold injuries, 10) lightning pathology, 11) rescue techniques in snow and ice fields, and 12) rescue techniques in rock environment. Demographics of the physicians included are given in Table 1. Fifteen of these ( 6 men and 9 women) passed the ATLS course within the last 3 years; the 15 other physicians ( 5 men and 10 women) did not.

\section{ATLS PRINCIPLES APPLIED IN THIS STUDY}

The first and key part of the assessment of patients presenting with trauma is called the primary survey. During this time, life-threatening injuries are identified and simultaneously resuscitation is begun. A simple mnemonic, ABCDE, is used as a memory aid for the order in which problems should be addressed: Aairway maintenance with cervical spine protection; $\mathrm{B}$ breathing and ventilation; $\mathrm{C}$-circulation with hemorrhage control; D-disability (neurologic evaluation); E-exposure/environmental control.

\section{SIMULATED TRAUMA CASES}

We designed 5 tasks representing acute life-threatening trauma problems encountered in mountain rescue. They were used to evaluate the physician's ability to adequately diagnose and treat a trauma situation, such as 1) airway problem, 2) breathing problem, 3) circulation problem, 4) environment problem, or 5) a combination of these problems. We created 8 simulated cases for each task. A written scenario of each case was obtained and validated by 3 emergency medical services (EMS) physicians with experience in mountain medicine. They also validated the ATLS course for students.

\section{STUDY DESIGN}

We created 2 groups: 1) the ATLS group, consisting of the 15 physicians who passed the ATLS course and the mountain medicine course, and 2) the non-ATLS group, consisting of the 15 physicians who did not perform the ATLS training but who did pass the mountain medicine course. Special attention was directed toward an equal degree of difficulty for the tasks in both studied groups. For each case, the treatment steps necessary to correctly perform the tasks (according to ATLS principles and the principles of mountain medicine) were defined by the 3 EMS physicians with experience in mountain medicine. These situations were investigated in the summer period at an altitude of $3600 \mathrm{~m}$ near the Refuge des Cosmiques (Chamonix-Mont Blanc, France). We compared both groups (ATLS and non-ATLS). The participating physicians accessed the study area by using the Aiguille du midi cable car; the material needed for the study (eg, ropes, hyperbaric chamber) was transported by the physicians and the investigating team. The study duration was 3 days. The cases were simulated by the investigating team and supervised by a mountain guide to ensure safety. Members of the investigating team played the role

Table 1. Demographics of participating physicians

\begin{tabular}{|c|c|c|c|}
\hline Variable & $\operatorname{ATLS}(n=15)$ & Non-ATLS $(n=15)$ & $\mathrm{P}$ \\
\hline Sex ratio $(\mathrm{M}: \mathrm{F})$ & $6: 9$ & $5: 10$ & $0.42^{a}$ \\
\hline Age (years), mean $\pm \mathrm{SD}$ & $40.0 \pm 4.8$ & $40.3 \pm 4.0$ & $0.83^{b}$ \\
\hline \multicolumn{4}{|l|}{ Experience } \\
\hline Working on trauma center, $\mathrm{n}(\%)$ & $5(33.3)$ & $6(40.0)$ & $0.63^{a}$ \\
\hline Working as mountain rescuer, $\mathrm{n}(\%)$ & $8(53.3)$ & $7(46.7)$ & $0.77^{a}$ \\
\hline Working in emergency department, $\mathrm{n}(\%)$ & $4(26.7)$ & $5(33.3)$ & $0.89^{a}$ \\
\hline Years since mountain medicine diploma, mean \pm SD & $4.9 \pm 2.1$ & $5.5 \pm 1.7$ & $0.35^{b}$ \\
\hline Years of clinical experience, mean $\pm \mathrm{SD}$ & $12.3 \pm 3.2$ & $13.1 \pm 3.3$ & $0.29^{b}$ \\
\hline
\end{tabular}


of the injured victim. Each of the physicians was investigated alone by another member of the study team acting as rescue nurse. The task of 2 members of the investigating team was to measure the time needed to achieve the mission and to judge the completeness of the treatment steps (as defined by the reference physicians).

\section{DATA ANALYSIS AND STATISTICS}

The sample size of 8 experiments for each task (airway, breathing, circulation, environment, and combination) used in the present study was calculated to be sufficient to reach the power threshold of 0.8 . We used the sample size calculation equation as described by Campbell et al. ${ }^{10}$ The number of participants needed for our study was determined using a specific power-based sample size calculation: $\mathrm{n}=\mathrm{f}(\alpha, \beta) \times\left(2 \mathrm{~s}^{2}\right) / \delta^{2}$, where $\alpha$ is the significance level (using a 2 -sided test), $1-\beta$ is the power of the test, $f=7.9$ for $\alpha=.05$ and $1-\beta=0.8, \delta$ is the smallest difference in means that we regard as being important to be able to detect, and $\mathrm{s}$ is the standard deviation measured (according to previous studies).

Statistical analysis was performed using Student's $t$ test. We used SPSS 19.0 statistical software (SPSS, Inc, Chicago, IL). All values are shown as medians and ranges. A probability value of less than .05 was considered significant.

\section{Results}

The characteristics of the physicians included in the present study are summarized in Table 1 . The results of our investigation are listed in Table 2. Because no significant differences were observed between sexes (men and women), these factors are not differentiated in the tables. In both groups, all treatment steps for each case were successfully identified. In 4 of the 5 tasks (airway, breathing, circulation, and combination), the ATLS group completed the task significantly faster. Only in the environment task cases did the ATLS group perform slower. However, this is the only not significant result. No failed case (lack of one of the defined treatment steps) could be observed.

\section{Discussion}

Our study shows that physicians who pass the ATLS student course have better results in terms of time to diagnose and to treat a simulated high altitude trauma situation. The positive impact of the ATLS education is particularly evident in cases dealing with the airway and cervical spine, breathing, circulation, and hemorrhage. However, the ATLS group did worse in simulated environment cases.

These results emphasize the lack of organized trauma treatment algorithms as a central problem in the actual mountain medicine education programs. Furthermore, there is a wide disparity in skill levels of physicians involved in mountain rescue and on-site treatment according to International Commission for Mountain Emergency Medicine standards ${ }^{5,6,11}$ : only $50 \%$ of physicians are obliged to perform a standardized training program in mountain emergency medicine beyond that required as part of their postgraduate training. This considerable lack of standardized training in specific mountain rescue-related problems and mountain trauma-related problems reflects in part the gap in unified and standardized international education guidelines (in Europe, for example, the mountain medicine diplomas are widely disparate from one university to another). The groups studied in the present investigation were homogeneous; the physicians assigned to each group had the same mountain medical education, and passed their final examination $4.9 \pm 2.1$ and $5.5 \pm 1.7$ years ago for ATLS and non-ATLS groups, respectively. No significant difference in terms of duration and quality of medical and professional experience was observed in both groups of physicians (Table 1). Interestingly, no physician worked as a full-time mountain physician, and that can be linked to the French medical system, which lacks board certification and full-time employment

Table 2. Median time spent to manage the simulated trauma cases at an altitude of $3600 \mathrm{~m}$ in both groups of physicians (ATLS and non-ATLS)

\begin{tabular}{lccr}
\hline Simulated trauma case & ATLS group $(\min )^{a}$ & ${\text { Non-ATLS group }(\text { min })^{a}}^{b}$ \\
\hline & & & \\
Airway and cervical spine & $10.40(3.44)$ & $14.76(4.30)$ & .044 \\
Breathing & $12.25(3.32)$ & $16.68(3.58)$ & .045 \\
Circulation & $10.33(2.63)$ & $15.68(3.11)$ & .023 \\
Environment & $6.22(2.63)$ & $5.36(1.91)$ & .730 \\
Combination & $14.32(3.51)$ & $18.33(3.91)$ & .001 \\
\hline
\end{tabular}

\footnotetext{
${ }^{a}$ Values are median (SD).

${ }^{b}$ Student's $t$ test; statistically significant when $P<.05$.
} 
opportunities in this field. The groups were also homogeneous in terms of mountain experience: although none of the physicians are a certified guide, they all have solid experience in mountaineering. Our data tend to indicate that specific supplementary trauma training associated with a standardized mountain medicine education improves the physician's competence in terms of treatment duration. As it is based on case simulation, the present study could be classified among the technologyenhanced simulation studies. Although scarce, the data on medical simulation in a mountainous environment show the use of simulation to be more effective and costefficient than other educational methods, as do the investigations in medicine training simulation reported in the literature. ${ }^{12,13}$

We hypothesized that an ATLS-based education supplement could overcome the lack of trauma-based principles in mountain education programs. It appears that the highly standardized treatment algorithm included in the ATLS principles is superior to standard mountain medicine education techniques owing to its effectiveness in precarious situations. As an answer to this lack of trauma training, ATLS in conjunction with a standardized mountain medicine education may constitute a reasonable baseline to overcome this problem. These results may indicate the need for specifically designed trauma education programs in the field of mountain medicine. In such programs, the ATLS principles could play a central role. However, the ATLS group did worse in the environment tasks. Our analysis is that ATLS lacks in specific preventive and therapeutic principles in relation to austere or extreme situations encountered in high altitude medicine (eg, effects of low temperature, wind, hygrometry, hypoxia). Thus, special attention should be given to these environmental factors to improve ATLS in austere places.

We may suppose that ATLS-based education could impact the overall treatment outcome. Further, the results of our study suggest that ATLS principles could impact the outcome in acute on-site trauma management in mountain medicine. Thus, we suggest that the on-site management of victims needs to be revised so that trauma management is given more prominence, ${ }^{14}$ and trauma education programs should be developed. ATLS could be proposed as a part of a new education program to overcome the lack of standardized trauma training of mountain physicians.

\section{LIMITATIONS OF THE STUDY}

There are several limitations to our study: 1) the cases used to test the physician's skills were simulated cases, reflecting only partially real in-field situations; 2) studying the time to recognize and treat a simulated problem is not an evaluation of the outcome of a trauma patient. Time to completion of medical tasks is only one outcome measure, and this may or may not represent a significant difference in patient care or outcome-a more comprehensive assessment could have been chosen and that should be a central point for future studies; and 3) the criteria retained to validate the successful completion of a simulated case do not fully integrate the dynamic evolution of injured mountain medicine patients-a more interactive simulation should be created in future investigations. These limitations should be kept in mind in the design of future studies, ideally conducted on site (remote high altitude location), and in real conditions of mountain medicine rescue. ${ }^{15}$ Despite these limitations, our study remains of interest by investigating a subject rarely studied and by proposing a way to overcome the problems related to the lack of standardized education.

\section{Conclusions}

In conclusion, ATLS principles adapted and implemented for high altitude medical education may have a positive impact on high altitude trauma treatment and thus may impact the outcome of these patients. These principles should ideally be included as case simulation education. The challenge is to adapt ATLS algorithms to trauma education programs in high altitude toward situations or rescues. Mountain ATLS (MATLS), in which trauma in mountain settings is addressed specifically and adequately, is a possible solution. Further studies exploring ATLS-adapted trauma education programs and testing this impact in real conditions (altitude, in-field rescue) are needed to test our hypothesis.

\section{Acknowledgments}

Our gratitude goes to Professor Jean-Paul Richalet (Chef du Service de Médecine du Sport, Hôpital Avicenne; Directeur du Laboratoire de Réponse Cellulaires et Fonctionnelles à l'Hypoxie, Bobigny) and Dr Paul Robach (École Nationale de Ski et d'Alpinisme, Chamonix) for their mountain medicine education (DUMM, Paris-Chamonix) and advice. We thank Professor Ulrich Theodor Hopt, MD (Director of the Department for Surgery, University Hospital Freiburg im Breisgau) for his support. We also thank anonymous referees for their helpful comments and tremendous work.

\section{Supplementary data}

Supplementary data associated with this article can be found in the online version at http://dx.doi.org/10.1016/ j.wem.2013.04.006. 


\section{References}

1. Thole RT. Preparation and medical management of events in mountain and high-altitude environments. Curr Sports Med Rep. 2004;3:128-133.

2. Windsor JS, Firth PG, Grocott MP, Rodway GW, Montgomery HE. Mountain mortality: a review of deaths that occur during recreational activities in the mountains. Postgrad Med J. 2009;85:316-321.

3. Marsigny B, Lecoq-Jammes F, Cauchy E. Medical mountain rescue in the Mont-Blanc massif. Wilderness Environ Med. 1999;10:152-156.

4. Demartines N, Meyer C, Scheiddegger D, Harder F. Helicopter and emergency physician at the accident site. Medical comparison between altitude and flat land emergency care [in German]. Helv Chir Acta. 1991;58:223-227.

5. Peters P. Personal and professional profile of mountain medicine physicians. Wilderness Environ Med. 2003; $14: 155-160$.

6. Elsensohn F, Niederklapfer T, Ellerton J, Swangard M, Brugger H, Paal P. Current status of medical training in mountain rescue in America and Europe. High Alt Med Biol. 2009;10:195-200.

7. Putzke M. Medical doctor in mountain rescue service-a profession's perspective [in German]. Anasthesiol Intensivmed Notfallmed Schmerzther. 2008;43:74-77.

8. Peters P, Plötz W. Mountain medicine education on Europe. Wilderness Environ Med. 1998;9:19-27.
9. Diplôme universitaire de médecine de montagne. Available at: http://www-smbh.univ-paris13.fr/formations/ du-diu/70-medecine-du-sport-et-des-voyages/193-du-demedecine-de-montagne.html. Accessed May 14, 2013.

10. Campbell MJ, Julious SA, Altman DG. Estimating sample sizes for binary, ordered categorical, and continuous outcomes in two group comparisons. BMJ. 1995;311:11451148 .

11. Brugger H, Elsensohn F, Syme D, Sumann G, Falk M. A survey of emergency medical services in mountain areas of Europe and North America: official recommendations of the International Commission for Mountain Emergency Medicine (ICAR Medcom). High Alt Med Biol. 2005;6:226-237.

12. Cook DA, Hatala R, Brydges R, et al. Technologyenhanced simulation for health professions education: a systematic review and meta-analysis. JAMA. 2011;306: 978-988.

13. McGaghie WC, Issenberg SB, Cohen ER, Barsuk JH, Wayne DB. Does simulation-based medical education with deliberate practice yield better results than traditional clinical education? A meta-analytic comparative review of the evidence. Acad Med. 2011;86:706-711.

14. Boyd J, Haegeli P, Abu-Laban RB, Shuster M, Butt JC. Patterns of death among avalanche fatalities: a 21-year review. CMAJ. 2009;180:507-512.

15. Trunkey DJ. Initial treatment of patients with extensive trauma. N Engl J Med. 1991;324:1259-1263. 